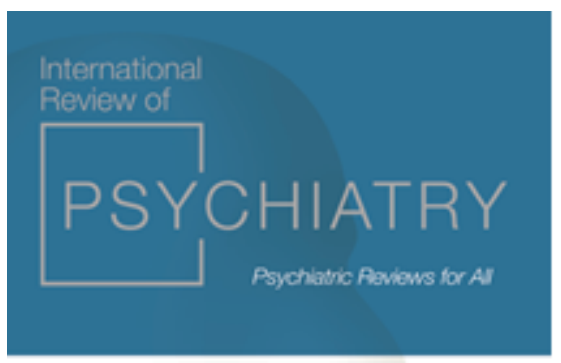

forom.

Protessor Dinesh Bhuga and or Margaret 8. Crisom

\title{
Circles of Support and Accountability (CoSA): A review of the development of CoSA and its international implementation
}

\begin{tabular}{|c|c|}
\hline Journal: & International Review of Psychiatry \\
\hline Manuscript ID & CIRP-2018-0037.R1 \\
\hline Manuscript Type: & Review \\
\hline $\begin{array}{r}\text { Date Submitted by the } \\
\text { Author: }\end{array}$ & 07-Nov-2018 \\
\hline Complete List of Authors: & $\begin{array}{l}\text { Azoulay, Natasha; Carleton University } \\
\text { Winder, Belinda; Nottingham Trent University, Psychology } \\
\text { Murphy, Lisa; The Royal, } \\
\text { Fedoroff, Paul; The Royal; University of Ottawa, Department of } \\
\text { Psychiatry }\end{array}$ \\
\hline Keywords: & $\begin{array}{l}\text { Circles of Support and Accountability, reintegration, restorative justice, } \\
\text { recidivism, social support, international }\end{array}$ \\
\hline
\end{tabular}

\section{SCHOLARONE \\ Manuscripts}


RUNNING HEAD: Circles of Support and Accountability

\title{
Circles of Support and Accountability (CoSA):
}

\section{A review of the development of $\mathrm{CoSA}$ and its international implementation}

\author{
${ }^{1}$ Natasha Azoulay, B.A. \\ ${ }^{2}$ Belinda Winder, Ph.D. \\ ${ }^{3}$ Lisa Murphy, M.C.A. \\ 3,4,5 J. Paul Fedoroff, M.D.
}

${ }^{1}$ Carleton University

${ }^{2}$ Sexual Offenses, Crime and Misconduct Research Unit, Department of Psychology, Nottingham Trent University

${ }^{3}$ Sexual Behaviours Clinic, Integrated Forensic Program, The Royal

${ }^{4}$ Department of Psychiatry/University of Ottawa

${ }^{5}$ Corresponding author: paul.fedoroff@theroyal.ca, Ph:1.613.722.6521, Fax: 1.613.798.2992 
Circles of Support and Accountability

\section{Declaration of Interests}

Authors 1, 3, and 4 report no conflict of interests. Author 2 is the trustee of a UK charity delivering Circles of Support and Accountability; she is also leading the national UK evaluation of Big Lottery funded Community-based Circles of Support and Accountability. 


\begin{abstract}
Circles of Support and Accountability (CoSA) was initially developed in Canada as a community-based program designed to assist in the community reintegration of individuals who are deemed a high or very high risk of sexual recidivism. This article outlines the historical foundations and frameworks of the CoSA model and examines the recruitment and training of CoSA volunteers. It reviews the impact that CoSA has on recidivism, as well as the psychosocial implications of the model on the former offenders participating in CoSA (the 'Core Members'), volunteers, and the community at large. International implementation of CoSA is addressed by a review of project initiatives undertaken around the world. This article concludes by addressing the future directions of CoSA, both within Canada and internationally.
\end{abstract}

Key words: Circles of Support and Accountability; reintegration; restorative justice; recidivism; social support; international 


\section{Circles of Support and Accountability (CoSA):}

\section{A review of the development of $\mathrm{CoSA}$ and its international implementation}

Initially developed in Ontario, Canada in the early 1990s, Circles of Support and

Accountability (CoSA) has emerged as a key contributor in the successful reintegration of highrisk former sex offenders into the community. This initiative has developed as a critical program both within its country of origin and in the countries that have since implemented their own CoSA programs internationally. CoSA emerged within a broader socio-political climate in which legislators and criminal justice officials alike were working to determine the most appropriate and successful means of protecting communities from the risk posed by individuals who have committed a sexual offense and who had reached the end of their sentence (Murphy, Martineau \& Fedoroff, 2008; Petrunik, Murphy \& Fedoroff, 2008).

In the late 1980s and early 1990s in Canada, the United States, and the United Kingdom, a small number of highly sensational cases were broadly publicized within the media. This led to public outcry for legislative changes that were intended to protect the community from victimization by those who the media portrayed as 'predatory' child sexual offenders (Petrunik et al., 2008). These events catalyzed the emergence of new legislation aimed at managing the risk posed by individuals prior to and post-release from custody. These legislative changes included: alterations in sentencing requirements, prohibition orders, peace bond modifications, detention of high-risk individuals until the end of their sentence (warrant expiry date [WED]), public notification of the release of high-risk individuals into the community, and registration of people convicted of sexual offenses (Murphy et al., 2008; Murphy et al., 2009).

Of these interventions, the detention of high-risk individuals until their WED, has been noted as being particularly problematic (Wilson, McWhinnie, Pichea, Prinzo, \& Cortoni, 2007). 
This mechanism ensures the short-term goal of public protection through incapacitation; however, it severely restricts the level of community supervision that occurs once the former offender is released. Cesaroni (2001) cautioned that, although this limits risk in the more immediate sense, a situation is created in which the former offender is left with no criminal justice support during the period when it is the most crucial. Often, many of these individuals are released into the community with little to no assistance or support for the process of reintegration (Wilson, Huculak \& McWhinnie, 2002).

Not only are they not under any criminal justice supports, but these individuals are often lacking, or have strained, familial or social supports which may lead to isolation and exacerbate their risk even further. Public protection from sexual victimization can best be ensured through a strategy that facilitates an offender's attempt to successfully reintegrate and become a productive member of society (Thurber, 1998). Unfortunately, despite attempts to improve management strategies for those who have committed a sexual offense, the detention of an individual until their WED still leaves a significant gap in successful reintegration practices and ultimately "sets both the community and the offender up for failure" (Wilson et al., 2007, p. 3).

It was within this legislative socio-political climate that CoSA emerged. The unique underpinnings of this program are its twin goals of preventing any further victimization; in conjunction with the proposition that 'no one is disposable'. To achieve these goals, CoSA promotes community safety and supports the former offender's daily needs, while holding them accountable for their actions. The process works to condemn the offense but, in the custom of restorative justice principles, accepts the person as a human being, deserving of a "second chance" to successfully reintegrate and live a pro-social, crime free life (Wilson et. al, 2007). 


\section{The Emergence of the Canadian CoSA}

Incarcerated Canadian offenders are automatically eligible to be released into the community, under correctional supervision, after serving two-thirds of their sentence (known as statutory release) (Corrections and Conditional Release Act, 1992). This permits offenders to be transitioned back into the community setting while still under correctional supervision, such as probation or parole. This process of assisting in the reintegration of people who have been convicted of a sexual offense is of significant importance as the risk for general and sexual recidivism is greatest during the first five years after their release from prison (Hanson \& Morton-Bourgon, 2007).

Legislative changes in sentencing permits Correctional Services Canada (CSC) to detain high-risk individuals until their Warrant Expiry Date (WED), based on their perceived risk to reoffend. The following criteria must be met under Canadian Bill C-67 in order for an offender to be held until WED:

a- must be serving a sentence for crimes against persons or violent crimes, and

b- commission of the offense caused serious harm or death to a person and there is reasonable grounds to believe the offender would commit another offense of that caliber before the end of the sentence, or

c- the offense was sexual in nature and involved a child and there is reasonable grounds to believe the offender would commit another offense of that caliber before the end of the sentence.

(CCRA, 1992, as amended)

In response to issues associated with the WED legislation, certain programs have emerged to aid those convicted of sexual offenses with the reintegration process. One particular approach was developed in 1994 following the release of Charlie Taylor, after serving a federal sentence for committing a sexual offense against a child. Prior to his release, the police implemented a public notification which resulted in an unsupportive media frenzy and around the clock surveillance of Taylor's home during his initial return to the community. 
In response to the media coverage and public outrage, Reverend Harry Nigh, pastor of the Mennonite Central Committee (MCC) in Hamilton, met with Charlie. Together with members of his congregation, a group of volunteers was formed to provide support and maintain accountability throughout Charlie's reintegration into the community. The work of these volunteers, later dubbed "Charlie's Angels”, provided a means by which to fill the void left by the WED legislation and protect the community through a process of ongoing support and accountability (Elliott et al., 2018). While the establishment of Charlie's CoSA has been documented considerably throughout the last two decades (see Cesaroni, 2001; Duwe, 2013; Wilson, Cortoni, \& McWhinnie, 2009), Reverend Nigh (1996) explained it best when he recounted, "I saw that despite the budget and numbers and physical force of our police force the real, liberating power lay within a little community that simply reached out in love" (p. 32).

Some months later the success of "Charlie's Angels" sparked the interest of Reverend Hugh Kirkegaard who incorporated the same model of support and accountability in response to the release of another individual whose sexual offending had resulted in some notoriety in Toronto, Ontario. As a result of Reverend Kirkegaard's position as Community Chaplain for the CSC, a contract was given to the Mennonite Central Committee of Ontario (MCCO) to establish a pilot project in south-central Ontario, with the aim of determining the program's effectiveness (Wilson, McWhinnie, Picheca, Prinzo, \& Cortoni, 2007). This program, officially formalized in 1996, is known today as the Circles of Support and Accountability (CoSA).

\section{CoSA's General Framework}

CoSA centers around one former offender, often one who is released following their WED, who becomes the designated Core Member (CM). Three to seven trained community 
volunteers form the inner circle around the CM. Typically there is also an outer circle of volunteers who may include trained professionals, such as psychiatrists, psychologists, physicians, correctional workers, and law enforcement officials (Clarke, Brown, and Völlm, 2015; Wilson et al., 2007).

Mission Statement. "Circles of Support and Accountability aims: To substantially reduce the risk of future sexual victimization of community members by assisting and supporting released individuals in integrating with the community and leading a responsible, productive, and accountable life" (“CoSA Mission and Objectives").

Objectives. "CoSA's objectives are: No More Victims and No One is Disposable" ("CoSA Mission and Objectives"). The model's core beliefs hold that change is possible; people who want help can ultimately lead prosocial, crime free lives, and thus deserve the support and resources to do so.

Target Population. CoSA targets higher-risk offenders (based on actuarial measures of risk with clinical override) in need of assistance with community reintegration; many of whom are designated as Long-Term Offenders (LTO), or Dangerous Offenders (DO). These individuals are released without access to resources of formal aftercare and are often likely to attract significant attention from the media (Wilson et al., 2007). CoSA is non-discriminatory and provides resources for any former offenders who voluntarily seek support and wish to be held accountable for their actions.

\section{CoSA's Theoretical Framework}

The CoSA model is founded on the theoretical framework of restorative justice. In accordance to the expectations of being a (predominantly) community-based program, CoSA 
places an emphasis on the needs and protection of the community. CoSA's definition of "community" is based on restorative justice, since it has been proposed that this term can be explicated as "a collective of interconnected individuals who are all of equal importance [leading to] the concept of mutual responsibility and the belief that people are accountable to one another" (Wilson, 2018, p. 22). The principle of restorative justice contends that injury to one is injury to the community at large (Wilson, 2018). By internalizing community values and transmitting them throughout the reintegration of offenders, CoSA is altering the way justice is typically delivered to this population; moving from punitive to more restorative.

CoSA further exemplifies restorative justice by adhering to its core three principles.

1. The principle of repair which focuses on healing the victims, offenders, and communities that were affected by a given crime. This principle further addresses the need to avoid additional victims by working with offenders to help build their communities.

2. The principle of stakeholder participation which provides the victims, offenders, and community with the opportunity to actively participate in the justice process.

3. The principle of transformation in community as well as government roles and relationships in which agencies provide trust in the community to accept a degree of responsibility in assisting the justice process.

(Newell, 2007).

Another key foundational framework for CoSA is the Risk-Need-Responsivity (RNR) model proposed by Bonta and Andrews (2007). The risk principle emphasizes the need to adjust the degree of an offender's therapy to his or her risk of recidivism. The need principle proposes the necessity of addressing an offender's criminogenic needs during the rehabilitative process, because those risk factors are dynamic and thus capable of change. Lastly, the responsivity principle seeks to maximize the effectiveness of therapy by tailoring the methods of treatment and intervention to address the former offender's particular circumstances.

The CoSA model adheres to the latter three principles and is designed to tailor the frequency of CoSA meetings and activities to a CMs individual level of risk, needs, and their 
responsivity and learning style (Höing, Vogelvang, \&Bogaerts, 2017a). The extent to which the program achieves this may vary between circles. For example, availability and/or commitment of volunteers may limit the frequency of meetings. The extent of volunteer knowledge and/or training in working with people with an intellectual disability may also limit their capabilities in being responsive to a $\mathrm{CM}$ who is intellectually disabled.

CoSA also incorporates a strength-based approach known as the Good Lives Model (GLM), which seeks to promote desistance of problematic behaviors by increasing an individual's attachment to social capital, with the ultimate aim of successfully reintegrating the former offender back into the community. At its core, the GLM is founded upon two main goals: to promote the basic needs that enable one to live a fulfilling life, and to provide former offenders with ways by which they can acquire and maintain fulfillment of these needs (Wilson, 2018). By affirming the mutual respect between CMs and Volunteer Members (VMs)focusing on forgiveness and acceptance, and advocating that the needs of former offenders are similar to the needs of non-offenders in the same community, CoSA upholds the core values of the GLM by helping former offenders find fulfillment in their lives post incarceration (Wilson, 2018).

\section{Making an effective CoSA}

The formation of an effective CoSA begins with the selection of a CM who voluntarily agrees to join the program, who is considered as high or at very high risk of recidivism, who feels socially isolated and who is motivated to pursue an offense-free lifestyle. The subsequent selection of trained VMs emphasizes the need for an appropriate balance between the independence and interconnectedness of members. Each VM must be able to allocate time to 
provide individualized attention to the $\mathrm{CM}$, while recognizing that these independent efforts occur in conjunction with the work of the group as a whole (Wilson, Picheca, \& Prinzo, 2005).

Group dynamics are fundamental not only to ensure that no members of the group are undermined, but also to ensure that no work accomplished by any individual VM contradicts or compromises the work of the Circle. The dynamic between the CMs and VMs is further complemented by the involvement of key outer-circle professionals. These treatment providers, community police officers, and probation officers are consulted to provide professional advice to facilitate the CM's reintegration. The additional participation of the "outer circle" of professionals ensures that the volunteers are able to meet their goals with the knowledge that they can receive aid from professionals during times of increased stress and possible increased risk of relapse (Wilson et al., 2005). For example, a COSA core member with bipolar disorder would be referred to a psychiatrist with experience in treating this psychiatric condition in conjunction with the assistance of the COSA "inner circle". In the case of the SBC in Canada, patients who are COSA core members are encouraged to invite their "circle" members to attend meetings with their psychiatrist. Importantly, the purpose of the joint meetings is not to "catch" the core member but instead to ensure that all members if the COSA program are on the same page.

\section{Funding of CoSA}

In Canada, CoSA projects were funded primarily by Corrections Service Canada (CSC) but at "arm's length". This was because, despite the fact that the government has no responsibility to manage former offenders, the funds were provided to the CoSA pilot project on account of the government's "moral" responsibility to both the former offenders and their respective communities. However, as the CoSA movement gained momentum and increased in 
popularity, additional support was granted by private donors. Although these generous contributions assisted in the maintenance of the project, financial stability remained a major concern for the long-term maintenance of the CoSA project (Wilson et al., 2005; Wilson et al., 2007). Fortunately, after a glowing external review, and a change in government, Federal support for the program is now in place, likely due to the demonstrated efficacy of COSA which has reduced both the financial burden of rehabilitating former offenders and the reoffence rate based on actuarial predictions.

\section{CoSA Volunteers}

\section{Volunteer Recruitment}

Several authors have recognized the task of volunteer recruitment as one of the greatest challenges faced by CoSA programs in Canada (Cesaroni, 2001; Wilson et al., 2005; Wilson et al., 2007). The majority of the VMs come from faith-based communities and students in local universities. The task of finding available volunteers can thus be challenging for members of inner-city congregations whose resources are already overwhelmed. It has also been suggested that some faith-based communities are not welcoming to the prospect of individuals convicted of sexual offenses. However, in some regions of Canada, CoSA volunteers may belong to other backgrounds. For instance, a local wellness college took leadership of its community’s CoSA project in Vancouver, British Columbia (Wilson et al., 2007).

CoSA recruitment at times results in the turning away of willing volunteers who do not meet the volunteer requirements (Wilson et al., 2005). See Wilson et al. (2007) for one list of the CoSA volunteer requirements. Once a volunteer is deemed suitable during the screening process and meets all the requirements, he or she will be invited to receive training. 


\section{Volunteer Training}

Volunteer training in Canada focuses on ensuring volunteers understand and adhere to firm and clear boundaries while also working to establish a foundation of trust with their CMs (Höing et al., 2017a). It has been contended that volunteer training should not be regarded as an alternative to professional care, but rather as a means to ensure that volunteers acquire enough knowledge about sexual offenses to effectively meet their responsibilities as VMs (Wilson et al., 2007). COSA training sessions aim to help VMs become more knowledgeable, thus assisting them to be effective volunteers to benefit their communities. Volunteer training is intended to meet the needs of the volunteers, to assist them to facilitate the aims of COSA. However, the implementation of CoSA volunteer recruitment and training varies within countries and internationally. For instance, the recruitment of CoSA VMs in Ottawa, Canada is a three-part process. The first phase consists of an information session for prospective volunteers. The second phase consists of a four-part basic training program that includes: fundamentals of CoSA, overview of sexual offending, legal controls for sexual offenders, and victim's perspective. Following the basic training program, CoSA project coordinators and board members conduct the screening process. All approved volunteers are invited to participate in the third phase of training, known as the practical applications of CoSA (for details see CoSA Ottawa's "Volunteer Training 2018”).

\section{Program Effectiveness}

\section{Impact on Recidivism}


Research has been conducted to examine the effectiveness of various facets of the CoSA program. One early two-part study examined the effectiveness of CoSA's pilot project (Wilson et al., 2005). The first part of the study examined the impact of CoSA on rates of recidivism. Sixty high-risk individuals who had committed sexual offenses and who were subsequently affiliated with CoSA were matched with 60 high-risk individuals who did not have the benefit of belonging to a CoSA group. Despite the higher actuarial risk assessment profile of the CoSA CMs, after a 4.5-year follow-up period, CMs in CoSA had significantly lower rates of all types of recidivism when compared to the control group. CMs who did reoffend committed less severe offenses than recidivists in the control group, with only three instances of sexual offenses (Wilson, et al., 2005). In this study, one CM's reoffense involved making an obscene phone call. This was deemed a reduction in severity of the offense from his previous hands-on sexual assault (Wilson, Bates \& Völlm, 2010).

Wilson, Cortoni, and McWhinnie (2009) completed a national replication study to determine whether the results from the pilot project were consistent throughout other CoSA projects in Canada. This study replicated the methodology of the Wilson, Bates and Völlm, 2010 study, adding the STATIC-99 (Hanson and Thornton, 1999) risk assessment tool. A group of 44 CMs from CoSA sites across Canada were matched with a group of similar offenders not involved in the CoSA program. They were evaluated for recidivism. Results over a three-year follow-up period, which controlled for actuarial risk level and time-at-risk, found that the CoSA group received $89 \%(n=5)$ fewer charges and convictions than the non-CoSA control group $(n=45)$. None of the CMs sexually recidivated during the period, compared to five in the control group. Violent recidivism in the CoSA group was $82 \%(n=2$ vs. $n=11)$ lower and general recidivism was $83 \%(n=2$ vs. $n=12)$ lower than in the control group. Consistent with these 
findings, Clarke et al. (2015) conducted a meta-analysis on the effectiveness of CoSA, which examined findings from fifteen different studies. The researchers reported that general and sexual recidivism rates were significantly lower for CMs than their respective control groups.

\section{Impact on CMs}

A second part of Wilson et al.'s (2005) study examined the impact of CoSA on its stakeholders. CMs reported that although they had mixed feelings about becoming involved with the program, the positive impact for them was profound. In fact, $90 \%(n=22)$ of CMs reported that they would have had difficulties reintegrating back into the community without the support and accountability of their VMs. Two-thirds $(66 \% ; n=16)$ of the CMs reported that they would likely have returned to crime without the support of the VMs. Similarly, VMs believed that their participation in CoSA contributed to an increase in public safety. However, one third $(33 \% ; n=6)$ of agency professionals in the study suggested a need to establish more clear personal boundaries between the CM and VMs.

Clarke et al.'s. (2015) meta-analysis investigated the psycho-social outcomes of CoSA on CMs. CoSA was found to be especially effective for factors such as emotional well-being, prosocial attitudes and activities, engagement in age-appropriate relationships, self-esteem, and successful resettlement processes.

Despite those findings, some have suggested that the voluntary nature of participation in CoSA may compromise results due to a self-selection bias (Kitson-Boyce, Blagden, Winder \& Dillon, 2018). Larger sample sizes and a more detailed explanation of the authors' selection of comparison groups have been recommended (Kitson-Boyce et al., 2018; McCartan, Kemshall, Westwood, MacKenzie \& Pollard, 2014). Despite these limitations, the preliminary and follow- 
up results of the CoSA model remain strongly supportive of CoSA's efficacy in reducing the risk and severity of sexual reoffence.

\section{Impact on VMs}

The positive findings of the effectiveness of the CoSA program are encouraging. However, there are additional potential benefits from the program that are not captured in standard recidivisim studies. A cross-sectional, quantitative study conducted by Höing, Bogaerts, and Vogelvang (2017b) examined the effect of volunteering in CoSA for VMs The data for the study were collected from an online questionnaire, in which 40 of the 118 invited VMs responded. The study examined overall satisfaction, determination to continue volunteering, mental well-being, job demands, internal job resources, external job resources, and volunteer connectedness. The results were positive, with VMs highlighting the beneficial impact of their work both on themselves and on CMs. "Levels of compassion" were high amongst volunteers, while "levels of burnout" were low. Social capital gains were reported. VMs did not report emotional, romantic, or sexual relationships being affected by their work with CoSA.

These findings are in line with an unpublished study by Murphy, Gray, and Fedoroff, which examined the psychological impact of involvement with CoSA on CMs and VMs. Results indicated that overall, participants in the study reported positive experiences associated with their CoSA involvement, especially with respect to personal growth, support, and relationshipbuilding.

The success of CoSA in Canada spurred an international interest in the model. Numerous pilot projects in several regions (see Table 1) were founded to implement CoSA on an international level. As CoSA gains increased acceptability and support internationally, the 
majority of research on the model has sought to establish the CoSA program's cost-effectiveness, impact on reducing recidivism, and its psycho-social effects on CMs and VMs. As VMs get to know CMs, and talk about their work to family and friends, there is a potential humanising effect on broader society. With this type of program, the public may begin to think of those who have committed a sexual offense as human beings who have done something dreadful, rather than the media perpetuated "incurable monster" that is often portrayed. This may help with reintegration and potentially further decrease recidivism itself. Research results to date are positive and reflect CoSA's success in reintegrating high-risk offenders into the community via a process that is financially beneficial to the community and which enhances the mental well-being of the VMs involved.

\section{International Implementation of CoSA}

As a result of the success of the CoSA initiative throughout Canada, a number of CoSA pilot projects have been implemented internationally. See Table 1 for a summary of the international pilot projects and research on their effectiveness.

\section{$<<<<<$ Insert Table 1 about here $>>>>>$}

\section{Circles United Kingdom}

Between 2002 and 2005, the Home Office (as it was termed at that time) funded three pilot projects in Britain: Hampshire, Thames Valley, and a national pilot project overseen by the Lucy Faithfull Foundation (Wilson, 2018). Over time, all three projects flourished, and the Home Office, impressed with the successes of the pilots, until recently (2018) funded additional CoSA projects in various institutions throughout Britain (Wilson, 2018). The UK projects are 
accredited by an umbrella organization, Circles UK, which has received funding from the

Ministry of Justice since 2007. Circles UK emerged as the "hub for the Circles project" (Hanvey, 2008, p. 39). Circles UK undertakes six principle objectives:

1. The development of circles across England and Wales, which is achieved by coordinating information and training regimens between projects.

2. Ensuring quality assistance by establishing and maintaining standards of practice.

3. Engaging in research and evaluation by promoting education related to CoSA.

4. Sustaining a positive public image of CoSA particularly through public awareness and media relations, by providing them with accurate information about the project.

5. Maintaining the influence of CoSA by cultivating and preserving relationships with law enforcement and government officials.

6. Sustaining all UK Circles while also supporting their expansion.

(Hanvey, 2008; Wilson, 2018)

In the UK, a novel form of CoSA has been offered: prison-based CoSA. The prison-based CoSA program begins several months before the $\mathrm{CM}$ is released. In this process the volunteers meet to begin establishing a CoSA bond with the $\mathrm{CM}$, while they are still in prison (Winder et al., 2015). UK-based organizations have also started offering CoSA to specialist groups, such as the elderly, intellectually disabled, and to young people (Winder et al., 2017). UK organizations offering CoSA, (such as the Safer Living Foundation [SLF], Circles South West, Circles South East; all of whom are charities) have built on the preliminary education sessions, and provide a series of non-mandatory "training days", which include training on housing, media and other specialized workshops; including a "Self-Regulation and Good Lives" workshop, a "Child Protection and Victims Unit" workshop, as well as enrollment in an "Aim Higher" national employment initiative.

These amendments to CoSA volunteer education demonstrate CoSA's versatility in providing support for CMs, who may be young, old, intellectually disabled, male, female, transgender etc. The SLF also examined the practice of CoSA using only British Sign Language for a $\mathrm{CM}$ who is deaf. Some UK projects also host Volunteer Actions Groups, which represent 
the CoSA VMs and address any issues they may have (Deborah, 2008). The Volunteer Action Group has ten aims, each of which are intended to contribute to the overall emotional well-being of the VMs involved with Hampshire and Thames Valley (HTV) Circles.

\section{CoSA United States}

In 2008, a pilot project known as the Minnesota Circles of Support and Accountability (MnCoSA) was implemented by the Minnesota Department of Corrections (MnDOC). The project was launched not only in response to the promising research conducted on the original CoSA pilot projects in Canada, but also to rectify the impact of community notification on increasing sexual offender recidivism (Duwe, 2013). In the state of Minnesota, offenders are placed on a three-tiered public notification based on their level of risk. Low-risk (Level 1) offender designation, for instance, requires notification only to local law enforcement and persons directly involved with the case. High-risk (Level 3) offender designation, on the other hand, are considered the highest risk and are subject to broad community notification policies which include media releases and appearance on publicly accessible sex offender registry websites.

Research by Duwe and Donnay (2008) suggested that Medium-risk (Level 2) offenders are the ones at highest risk of sexual recidivism following their release into the community; a rate that nearly doubles for Level 3 offenders. Level 3 offenders are held more accountable because a Level 3 assignment requires broad community notification and community involvement, whereas a Level 2 assignment requires only a limited public notification and less community engagement. Based on these findings, the MnDOC implemented the CoSA model to specifically target Level 2 offenders. 
Although MnCoSA was initially modeled on the Canadian CoSA system, it varies in its execution. Some of the variation involves government-based and not based on faith-based communities. MnCoSA does not place an emphasis on an offender's expired sentence. Instead, the USA targets offenders released from prison and placed on intensive supervised release (ISR). Lastly, MnCoSA begins working with offenders four weeks prior to their ISR, meaning they can access treatment before return to their communities (Duwe, 2013).

Despite these differences, research on the MnCoSA pilot project is quite promising (Duwe, 2013). The results of the MnCoSA pilot project (Duwe, 2013) demonstrate the model's effectiveness at reducing recidivism, while also proving to be financially beneficial to the MnDOC. A recent RCT analysis sought to update the results from Duwe's (2013) study. Duwe (2018) found that, after the six-year follow-up period, participation in MnCoSA significantly decreased recidivism, having reduced the risk of committing a new sexual offense by $88 \%$ $(n=100)$.

While Duwe $(2013,2018)$ cautions readers to acknowledge the smaller sample sizes of the studies $(n=62 ; n=100)$, it is worth noting the overall success of the project, insofar as the MnCoSA, averages approximately eight circles per year since its launch. However, Elliott and Zajac (2015) suggest there may be some difficulty implementing CoSA nationwide. More research is needed to adequately determine the model's effectiveness and whether the results can be generalized to states throughout the country.

\section{CoSA New Zealand}

The CoSA pilot project was implemented in New Zealand (NZ) in 2008, in response to several offenders who underwent a treatment program at the TePiriti Special Treatment Unit but who did not have adequate community support following successful completion of the program. 
The project was implemented gradually and cautiously in an attempt to reduce the media outrage and public protests exhibited during the release of the preliminary CMs of CoSA projects in Canada and the UK (van Rensburg, 2012). The project thus differs from CoSA in Canada as it targets high-risk offenders who have demonstrated pro-social behavior throughout their treatment but who often remain on lifelong parole. Circles in NZ are formed prior to the offender's release into the community, and VMs are often affiliated with church groups.

The volunteer selection process and training regime is adapted from the Canadian CoSA model. While finding suitable volunteers posed a problem for the NZ pilot project, the greatest challenge was bridging the gap between an offender's probation officers and VMs (van Rensburg, 2012). Most importantly, CoSAs in NZ have no community-based groups currently offering to assist in the maintenance of the project, unlike the MCC in Canada. For this reason, van Rensburg (2012) has noted some community hesitation and funding challenges in response to the pilot project. This problem could be somewhat rectified by acquiring more support from larger community-based organizations.

\section{CoSA Scotland}

Prior to the conception of the first official Scotland CoSA Circle in 2010, CoSA was informally run by churches throughout the country. In 2008, Armstrong, Chistyakova, Mackenzie, and Malloch published an extensive preliminary report on behalf of the Scottish Centre for Crime and Justice Research, which advocated for the implementation of a formal CoSA in the country. However, despite this advocacy, the Scottish Government decided not to fund CoSA pilot projects in Scotland (Armstrong \& Wills, 2014). In response to the government's decision, a pilot project implemented "Fife" by the Scottish community justice organization, Sacro. The model of the Fife Circles is quite similar to the design of Circles UK, 
with volunteer training consisting of the protocols outlined in the Circles UK Handbook. Although no published research exists with respect to the quantitative successes of the pilot projects thus far, Armstrong and Wills (2014) published a final report, which qualitatively details the pilot's endeavors since its inception in 2010. In the report, Armstrong and Wills (2014) acknowledge that those involved in the pilot project were supportive of continuing with the CoSAs, because they felt the project contributes successfully to the management of risk.

\section{CoSA Netherlands}

In 2009, a two-year pilot project was launched in the Netherlands (NL) that was implemented by Circles NL, the national bureau for CoSA in the Netherlands, and was granted financial support from the Dutch Ministry of Justice. The projects are overseen by the Dutch probation organization, thus designating it as a government-based rather than community-based program. A preliminary report by Höing and Vogelvang (2011), demonstrated that similar to the other pilot projects, there were challenges in finding VMs for both pilot projects.

While research has yet to be published regarding the effectiveness and success of the pilot projects, Höing and Vogelvang (2011) described a longitudinal research study that is currently underway. Preliminary findings in the report illustrate that, despite certain differences in the dynamics of the CoSA, there was an emphasis on a monitoring and supportive approach that was consistent between both pilot projects. The monitoring function, enabled VMs to communicate concerns about risk factors to the outer circle professionals who were unaware of them, was successful in both CoSAs. The supportive function, which emphasizes trust between CMs and VMs, was effective in only one of the two projects. Results for the second CoSA are mixed; however, one finding was that once the CM was more consistently held accountable, he eventually became more willing to contribute to the Circle. Because of the delayed process in 
developing trust, the effectiveness of support in the second project remains unclear. The final outcomes of this study, once published, should help to determine the feasibility of long-term success for Circles NL.

\section{Conclusion}

CoSA emerged in the late nineties to fill the gap created by the practice of the Federal parole board to keep high-risk sex offenders to warrant expiry. Since its inception, CoSA has proven to be more effective than originally anticipated. Over the last 30 years, CoSA programs and associated research has emerged internationally. The randomized controlled trial (RCT) study by Duwe (2018), taken together with existing literature to date, indicates that CoSA is effective in reducing sexual and general recidivism. The efficacy of CoSA must be considered in the context of differences between criminal justice programs in different countries and various international approaches to delivering CoSA. There is a need for a consistent approach to delivering the universally effective aspects of $\operatorname{CoSA}$, as well as ongoing reassessment to maintain the effectiveness of each specific program in each specific region for each specific CM.

The need to understand who benefits the most (and indeed who does not benefit, and what lessons can be learned from the failures) should be an intrinsic part of the evaluation of each program. In addition to reduced recidivism, the well-being and successful reintegration of the CMs into society, and the effect of CoSA on the friends and families of CM's are important program outcomes that have not been fully evaluated to date.

Finally, perhaps one of the most valuable, but less frequently considered, benefits of CoSA may be the "ripple effect" that creates changes in attitudes towards people who have committed sexual offenses. Volunteers speak to friends and family (who may at first be shocked and dismayed by the choice of volunteering role); over time, friends and family begin to adopt a 
more understanding attitude to the CM. This attitude may be communicated to others and so on. The importance of reducing social and emotional isolation in those convicted of a sexual offense is clear; softening and humanizing the public's attitudes to people who have committed a sexual offense is an important aspect of CoSA.

\section{References}

Armstrong, S., Chistyakova, Y., Mackenzie, S., \& Malloch, M. (2008). Circles of Support \& Accountability: Considerations of the feasibility of pilots in Scotland (Research Report). Glasgow: Scottish Centre for Crime and Justice Research.

Armstrong, S., \& Wills, D. (2014). A review of the Fife Circles of Support and Accountability project commissioned by Sacro - Final report (Research Report). Glasgow: Scottish Centre for Crime and Justice Research.

Bonta, J., \& Andrews, D. A. (2007). Risk-need-responsivity model for offender assessment and rehabilitation (User Report 2007-06). Ottawa, Ontario: Public Safety Canada.

Cesaroni, C. (2001). Releasing sex offenders into the community through "Circles of Support": A means of reintegrating the "worst of the worst." Journal of Offender Rehabilitation, $34(2), 85-98$.

Clarke, M., Brown, S., \& Völlm, B. (2015). Circles of Support and Accountability for sex offenders: A systematic review of outcomes. Sexual Abuse, 29(5), 446-478.

Corrections and Conditional Release Act, S.C. 1992

Corrections and Conditional Release Act, S.C. 1992, c.20, as amended. 
Circles of Support and Accountability

CoSA Canada. (n.d.). Mission and Objectives. Retrieved from

http://cosacanada.com/cosa-canada-mission-statement/

Deborah. (2008). HTV Circles - Six Years of Safer Communities: Six Year Report (Research Report). London: Quaker Peace and Social Witness.

Duwe, G. (2013). Can Circles of Support and Accountability (CoSA) work in the United States? Preliminary results from a randomized experiment in Minnesota. Sexual Abuse: A Journal of Research and Treatment, 25(2), 143-165.

Duwe, G. (2018). Minnesota Circles of Support and Accountability (MnCoSA) at 50: Updated Results from a Randomized Controlled Trial (Research Report). St. Paul, Minnesota, USA: Department of Corrections. Retrieved from https://mn.gov/doc/assets/2018\%20MnCOSA\%20Outcome\%20Evaluation_tcm1089326700.pdf

Duwe, G., \& Donnay, W. (2008). The impact of Megan's Law on sex offender recidivism: The Minnesota experience. Criminology, 46, 411-446.

Elliott, I. A., \& Beech, A. R. (2013). A U.K. cost-benefit analysis of circles of support and accountability interventions. Sex Abuse, 25(3), 211-229.

Elliott, I. A., \& Zajac, G. (2015). The implementation of Circles of Support and Accountability in the United States. Aggression and Violent Behavior, 25, 113-123.

Hanson, R. K., Harris, A., Helmus, L., \& Thornton, D. (2014). High-risk sex offenders may not be high risk forever. Journal of Interpersonal Violence, 29(15), 2792-2813.

Hanson, R.K., \& Morton-Bourgon, K.E. (2007). The accuracy of recidivism risk assessments for sexual offenders: A meta-analysis 2007-01 (Research Report). Public Safety and Emergency Preparedness Canada. Ottawa, Ontario. 
Hanson, R. K., \& Thornton, D. (1999). STATIC-99: Improving actuarial risk assessments for sexual offenders (Research Report No. 1999-02). Ottawa, Ontario, Canada: Corrections Research, Public Safety Canada. Retrieved from http://ww2.ps-sp.gc.ca/ publications/corrections/199902_e.pdf

Hanvey, S. (2008). HTV Circles — Six Years of Safer Communities: Six Year Report (Research Report). London: Quaker Peace and Social Witness.

Höing, M., Bogaerts, S., \& Vogelvang, B. (2017b). Volunteers in Circles of Support and Accountability: Job demands, job resources, and outcome. Sexual Abuse, 29(6), 541-562.

Höing, M., \& Vogelvang, B. (2011). CoSA in Nederland: Implementatieonderzoek pilotfase(Research Report). Hertogenbosch: Programmabureau Circles-NL.

Höing, M., Vogelvang, B., \& Bogaerts, S. (2017a). "I am a different man now” — Sex offenders in Circles of Support and Accountability: A prospective study. International Journal of Offender Therapy and Comparative Criminology, 61(7), 751-772.

Kitson-Boyce, R. (2018). Do CoSA Work? A Review of the Literature. In H. Elliott, K. Hocken, R. Lievesley, N. Blagden, B. Winder, \& P. Banyard (Eds.), Sexual Crime and Circles of Support and Accountability (pp. 63-96). Basingstoke: Palgrave Macmillan.

Macrae, R. (2008). HTV Circles - Six Years of Safer Communities: Six Year Report (Research Report). London: Quaker Peace and Social Witness.

McCartan, K., Kemshall, H., Westwood, S., Solle, J., MacKenzie, G., \& Pollard, A. (2014). Circles of Support and Accountability (CoSA): A case file review of two pilots. Ministry of Justice Analytical Summary, London: Ministry of Justice.

Murphy, L., Brodsky, D., Brackel, J., Petrunik, M., Fedoroff, P., \& Grudzinskas, A. (2009). Community Based Management of Sex Offenders: An Examination of Sex Offender 
Registries and Community Notification in the United States and Canada. In F.M. Saleh, A.J. Grudzinskas, J.M. Bradford, \& D.J. Brodsky (Eds.), Sex Offenders: Identification, Risk Assessment, Treatment, and Legal Issues (pp. 412-424). New York, NY: Oxford University Press.

Murphy, L., Gray, J. \& Fedoroff, P. An Examination of the Psychological Impact of Circles of Support and Accountability (CoSA) on the program's core members and volunteers. Funded by Canadian Psychiatric Association, unpublished manuscript.

Murphy, L., Fedoroff, P. \& Martineau, M. (2009). Canada’s Sex Offender Registries: Background, Implementation, and Social Policy Considerations. Canadian Journal of Human Sexuality, 18, 61-72.

Newell, T. (2007). Forgiving Justice: A Quaker vision for criminal justice Swarthmore Lecture 2000. London: Quaker Books

Nigh, H. (1996). Circles of Support and Accountability for released sex offenders: One community's story. In Church Council on Justice and Corrections, Satisfying Justice, $31-33$.

Petrunik, M. (2003). The hare and the tortoise: Dangerousness and sex offender policy in the United States and Canada. Canadian Journal of Criminology and Criminal Justice, 45(1), 43-72.

Petrunik, M., Murphy, L., \& Fedoroff, P. (2008). American and Canadian Approaches to Sex Offenders: A Study of the Politics of Dangerousness. Federal Sentencing Reporter, 21(2), $111-123$.

Thurber, A. (1998). Understanding offender reintegration. Forum on Corrections Research, $10(1), 14-18$. 
van Rensburg, J. (2012). The dawn of Circles of Support and Accountability in New Zealand. Sexual Abuse in Australia and New Zealand, 4(2), 30-35.

Volunteer Training. (2018, September 06). Retrieved from https://cosa-ottawa.ca/training/basictraining/

Wilson, C. (2018). A History of the Development of Circles of Support and Accountability. In H. Elliott, K. Hocken, R. Lievesley, N. Blagden, B. Winder, \& P. Banyard (Eds.), Sexual Crime and Circles of Support and Accountability (pp. 15-41). Basingstoke: Palgrave Macmillan.

Wilson, R., Huculak, B., \& McWhinnie, A. (2002). Restorative justice innovations in Canada. Behavioral Sciences and the Law, 20,363-380.

Wilson, R., McWhinnie, A., Picheca, J., Prinzo, M., \& Cortoni, F. (2007). Circles of Support and Accountability: Engaging volunteers in the management of high risk sex offenders. The Howard Journal, 46(1), 1-15.

Wilson, R., Picheca, J., \& Prinzo, M. (2005). Circles of Support and Accountability: An evaluation of the pilot project in South-Central Ontario (Research Report). Ottawa: Correctional Services Canada.

Wilson, R., Cortoni, F., \& McWhinnie, A. (2009). Circles of Support and Accountability: A Canadian national replication of outcome findings. Sexual Abuse: A Journal of Research and Treatment, 21(4), 412-430. 
RUNNING HEAD: Circles of Support and Accountability

Table 1: Regions with Launched CoSA Pilot Projects

\begin{tabular}{|c|c|c|c|}
\hline Region & Pilot Project Researched & $\begin{array}{l}\text { Reduction in } \\
\text { Recidivism }\end{array}$ & $\begin{array}{l}\text { Cost } \\
\text { Effective }\end{array}$ \\
\hline CANADA & $\begin{array}{l}\text { Yes } \\
\text { Location: South-Central Ontario } \\
\text { Year of Pilot Project Launch: } 1996\end{array}$ & $\begin{array}{l}\text { Yes } \\
\text { Source: Wilson et } \\
\text { al., 2005; Wilson } \\
\text { et al., 2009; Clarke } \\
\text { et al., 2015 }\end{array}$ & $\begin{array}{l}\text { Yes } \\
\text { Source: Wilson et } \\
\text { al., 2005; Wilson et } \\
\text { al., 2009; Clarke et } \\
\text { al., 2015 }\end{array}$ \\
\hline $\begin{array}{l}\text { UNITED } \\
\text { KINGDOM }\end{array}$ & $\begin{array}{l}\text { Yes } \\
\text { Location: Hamilton and Thames } \\
\text { Valley } \\
\text { Year of Pilot Project Launch: 2002- } \\
2005\end{array}$ & $\begin{array}{l}\text { Yes } \\
\text { Source: Elliot \& } \\
\text { Beech, 2013; see } \\
\text { also Kitson-Boyce, } \\
2018\end{array}$ & $\begin{array}{l}\text { Yes } \\
\text { Source: Elliott \& } \\
\text { Beech, 2013; see } \\
\text { Kitson-Boyce, } 2018\end{array}$ \\
\hline UNITED STATES & $\begin{array}{l}\text { Yes } \\
\text { Location: Minnesota } \\
\text { Year of Pilot Project Launch: } 2008\end{array}$ & $\begin{array}{l}\text { Yes } \\
\text { Source: Duwe, } \\
\text { 2013; Duwe, } 2018\end{array}$ & $\begin{array}{l}\text { Yes } \\
\text { Source: Duwe, } \\
\text { 2013; Duwe, } 2018\end{array}$ \\
\hline NEW ZEALAND & $\begin{array}{l}\text { Yes } \\
\text { Location: TePiriti } \\
\text { Year of Pilot Project Launch: } 2008\end{array}$ & N/A & $\mathrm{N} / \mathrm{A}$ \\
\hline SCOTLAND & $\begin{array}{l}\text { Yes } \\
\text { Location: Fife } \\
\text { Year of Pilot Project Launch: } 2010\end{array}$ & $\mathrm{~N} / \mathrm{A}$ & $\mathrm{N} / \mathrm{A}$ \\
\hline NETHERLANDS & $\begin{array}{l}\text { Yes } \\
\text { Location: Brabant } \\
\text { and Rotterdam/Dordrecht } \\
\text { Year of Pilot Project Launch: } 2009\end{array}$ & $\mathrm{~N} / \mathrm{A}$ & $\mathrm{N} / \mathrm{A}$ \\
\hline IRELAND & 8 & $\mathrm{~N} / \mathrm{A}$ & $\mathrm{N} / \mathrm{A}$ \\
\hline AUSTRALIA & $\mathrm{No}$ & $\mathrm{N} / \mathrm{A}$ & $\mathrm{N} / \mathrm{A}$ \\
\hline SOUTH AFRICA & No & $\mathrm{N} / \mathrm{A}$ & $\mathrm{N} / \mathrm{A}$ \\
\hline CHINA & No & N/A & $\mathrm{N} / \mathrm{A}$ \\
\hline JAPAN & No & 2 & $\mathrm{~N} / \mathrm{A}$ \\
\hline
\end{tabular}

